\title{
Respiratory therapy
}

\section{Introduction}

I get up around 4:15 am and hit the snooze button on my phone alarm exactly 3 times before getting up. I get ready for work and head out around five am. Sounds pretty routine, right? One difference though, my job is one of those jobs that involve possible life and death situations that I must face if not once but possibly several times throughout the day. I am a Respiratory Therapist. Other well-known jobs with the same possible scenarios that are often romanticized in books, tv shows, and movies are comprised of peace officers, firefighters, military personnel, doctors, nurses, paramedics, and emergency medical transport teams, also known as EMT's. Most people know what these jobs consist of, but if you ask anyone what a respiratory therapist is, most have no idea. This can be very frustrating always having to explain what a respiratory therapist is and what we do on a daily basis. I'm on a mission to change that.

First, a little history about myself, when I was a junior at Upper Darby High School in Pennsylvania I was preparing myself to graduate high school and go on to University. Playing Soccer, studying biology and anything technical was my thing. I took electronic classes, computer programming and other advanced science classes in high school. My mother worked at Hahnemann University Hospital in Philadelphia in the clinical research department. When I wasn't in school I was always looking forward to going to the hospital with my mom. Over the years I became familiar with some of the Doctors and was invited to sit in on lectures with medical students. This exposure helped me later in my life although I didn't know it then.

In my senior year of high school I realized that I would not be going to college the way that I would have liked to. Reality is heartbreaking. But with no scholarships for men's soccer, and schools being very expensive in the area at the time, I decided to join the United States Air Force. I was 17 and wanted adventure. I was trained in radar and inertial navigation systems, also known as avionics. The training and experience that I gained in the Air Force eventually led me to a position in the aircraft manufacturing company McDonnell Douglas Aircraft Company in Long Beach Ca. I landed an entry level position on the MD-80's, installing interior electrical systems; within 4 months I was promoted to work on the first C-17 test plane one or T-1, I think just to shut me up and get me out of the HR office. I worked on and assisted in development of all electrical and avionics systems on the first C-17 (T-1), through the third production aircraft. The year was 1990 and I was averaging \$18 an hour plus overtime. Plus benefits that were real benefits back then, not like now. I had my eyes on the space lab program located in Huntington Beach California. I wanted to be a part of the development and manufacturing team on the guidance and navigation control systems on the space lab module. My dream job!! My wife and I were raising a young family and considering buying our first house in Corona $\mathrm{Ca}$, everything was coming together, but then reality kicked in. The cold war was over, the wall was down in Berlin and the USSR was no more. Life was about to change, for everyone.

After being laid off from McDonnell Douglas for the second time, I took a job with a subcontractor out of St Louis Missouri to work on F-18's for the Spanish Air Force. Me and my family which included
Volume 4 Issue 5 - 2017

\section{Paul bounds}

Phoenix VA Medical Center, USA

Correspondence: Paul Bounds, Phoenix VA Medical Center, Respiratory therapist in Phoenix, Arizona, USA, Email psbrrt@gmail.com

Received: June 18, 2017| Published: September 27, 2017

three small children at the time were about to live in Spain for about two and a half years. I was performing avionic and electrical modifications six days a week, 12 to 14 hours a day. I thought two years would be sufficient time for the economy to stabilize resulting in improved employment opportunities upon our return. But, when we returned to the United States the economy was still in pretty bad shape, not many jobs in avionics or aircraft maintenance were available at that time. I realized I had to go back to school. With some research and help from the unemployment office in Redlands California I narrowed my decision to Biomedical Technician or Respiratory Therapy. Both had a technical aspect to it that I liked, but respiratory therapy had blood gas interpretation along with direct patient care that would provide job security. With a clinical background in blood gas interpretation and my technical background in avionics I was still dreaming of one day working in some sort of capacity on the development and manufacturing of components of the space lab module, with heavy emphasis on the cognitive impact on operation of all flight control and communication systems in relation to extended exposure in a weightlessness environment in space. Upon graduating and becoming a licensed respiratory care practitioner, I returned to McDonnell Douglas in Huntington Beach California to see if there were any positions available in the development or manufacturing in the space lab division. With no jobs available for me at that time within McDonnell Douglas, I decided that I would give up my thoughts of ever working on the space lab program. Now I would concentrate my efforts on seeking employment within the hospital setting. The year was 1995 and my Respiratory Career was about to begin.

I began working in hospitals in California then Arizona gaining experience in many areas of respiratory care. I worked wherever they would allow me to work critical care, home care, long term care, intensive care (neonatal, pediatric, and adult), pretty much every where I could. Long term critical care is actually where my experience with airway management and my self-confidence flourished. Next thing I know twenty years has gone by, and my youngest child is starting college now. So, I pause and look back, and my sense of accomplishment is great, but my frustrations within the respiratory field are equally as great. This paper is a meager attempt at selftherapy along with an explanation on how I feel the profession of respiratory therapy should be utilized now and in the future, in all areas of the medical community.

Now for a little history on how respiratory care became what it is today. The National Board of Respiratory Care (NBRC) was originally called the American Registry of Inhalation Therapists (ARIT). It was a voluntary health certifying board which was created 
in 1960 to evaluate the professional competencies of respiratory therapists on a national level. This board was created to provide a standard of practice within the field of respiratory care. But if we look back even further it all really started in 1943 at the Michael Reese Hospital in Chicagowhen Dr. Edwin R. Levine began training technicians in basic inhalation therapy for post-surgical patients, usually this involved oxygen therapy and rescue breathing.Physicians along with therapists recognized the need to formalize the training and registration of practitioners involved in the care and support of patients with respiratory disorders. But it wasn't until 1947 in Dr. Albert Andrews's book "Manual of Oxygen Therapy", where it outlined the structure and purpose of having an inhalation department within the hospital setting itself. After that it took about ten years to determine and implement the first trials for the creation and enactment of schools specifically aimed at inhalation therapy. In 1982, California became the first state to pass a licensure law governing the profession of respiratory care. In 2004, the state of Vermont became the $48^{\text {th }}$ state to pass a legal credentialing law governing respiratory care. Hawaii and Alaska are still in the process of finalizing licensure at this time.'

In 2015 , the NBRC was identifying only one credentialing exam the Registered Respiratory Therapist (RRT) thus eliminating the Certification exam (CRTT). Since 1995 most respiratory therapy programs in the nation have been associate degreed RRT programs, thus eliminating the need for a separate entry level examination for nearly twenty years. My only explanations for not eliminating the separate CRTT exam during that time were for a couple of reasons. One, a much-needed revenue source for the credentialing board and academia, and second, to curtail overhead costs by maintaining lower wages in the employment sector, but that's just my opinion. "Effective January 2015, the name of the examination that candidates take for Certification changes from the Entry Level CRT Examination to the Therapist Multiple-Choice Examination (TMC). The Therapist Multiple-Choice Examination is designed to objectively measure essential knowledge, skills, and abilities required of entry-level respiratory therapists, as well as determine eligibility for the Clinical Simulation Examination. There are two established cut scores for the Therapist Multiple-Choice Examination. If a candidate achieves the lower cut score, they will earn the CRT credential. If a candidate achieves the higher cut score, they will earn the CRT credential AND become eligible for the Clinical Simulation Examination. Once the candidate successfully passes the Clinical Simulation Examination and provided that all other eligibility requirements are met, then they are awarded the RRT credential. ${ }^{2}$

My goal for writing this paper is that I will have informed the general public, along with academia and the healthcare institutions, on what exactly a respiratory therapist is. Also, how the educational requirements have progressed over the years to become a licensed care practitioner and how respiratory therapists contribute within the health care industry daily. I also hope to educate all readers on the actual role verses the perceived role of respiratory therapists in the community. I will also discuss the role or direction I believe that the respiratory therapist will need to advance within the near future for the betterment of health care needs for the community within the near future. Some examples of this progression towards the future would be Pulmonary Assistants, mainly for assisting or advising medical doctors, nurses and physician assistants with patient management (inpatient and outpatient) in all departments that manage pulmonary patients. Critical Care Pulmonary Assistants, providing assistance to cardiopulmonary intensives in the ICU setting. And last, I will demonstrate the pay disparity between registered nurses and registered respiratory therapists that have similar educational backgrounds and working environments. The pay disparity examples used in this paper is why I believe there are recruitment and retainment issues of well qualified candidates within the field. Not to discount the many other pay disparities in countless other career fields within the United States, but this paper is focused on respiratory therapy only.

\section{I ${ }^{\text {st }}$ Topic}

What is a Respiratory Therapist? The actual role for a respiratory therapist varies greatly from hospital to hospital, public or private, even hospitals within the same zip code policies and procedures can fluctuate. If anyone has even heard of respiratory therapy as a profession in passing, the perception is that respiratory therapists merely administer svn's (small volume nebulized bronchodilators) when ordered, and administer general oxygen therapy only. A long time ago that may have been the case, but now, that is actually far from the truth. Most hospitals today will have the respiratory therapists involved with patients potentially progressing to a critical state or already in a critical state. This usually involves a therapist to asses, and treat, the patient's current condition. This can include anything from administering a small volume nebulized bronchodilator treatment (SVN's), advanced airway management to arterial blood gas draws, interpretation of the gas sample in the lab, then providing a corrective action for treatment plan for the patient in question. This assessment, advisement, and treatment are common for all respiratory therapists in every hospital within the United States. The level of treatment along with patient intervention depends as stated before, on each individual medical facilities policies and procedures. Some examples of respiratory procedures that are within scope of practice includes obtaining arterial blood gases along with interpretation and corrective treatment, arterial line placement and monitoring, non-invasive and invasive airway management such as intubation. Intubation is the placement of an artificial airway, the most common being an endotracheal tube for airway protection, and to facilitate artificial ventilation or life support. Life support for a respiratory therapist in an intensive care unit usually involves management of ventilators to maintain life sustaining parameters for the acutely ill patient. Ventilators are highly technical machines commonly found in ICU's at the patient's bedside, providing much needed ventilation and oxygenation to maintain life parameters until the patient can breathe on their own again.

Respiratory therapists work in all areas of the hospital with all age populations. These areas include all intensive care units, adult, pediatric, and neonatal units, labor and delivery, long term critical care, and so on. During some shifts a therapist, depending on staff availability; will cover more than one area of the hospital or age demographic. For example, in one shift, you may cover pediatrics and adult care, the next day you may be in the ER or the neonatal intensive care unit. One thing that is consistent is that we always work with the most critical patients every shift on every unit of the hospital. We respond to all code blues and rapid responses, not only in the departments we are responsible for that assigned shift, but the entire hospital. I always tell patients, the least you see of me the better. Meaning you're not critically ill and probably stable. Respiratory therapists have to maintain competencies and proficiencies in advanced life support on all age groups, these include the basic life support (BLS), advanced cardiac life support (ACLS), pediatric advanced life support (PALS) and the neonatal resuscitation program (NRP). 
Every two years we have to recertify in all of these programs to maintain employment. Unlike other ancillary professions within the hospitals such as lab technicians, x-ray technicians, physical therapists, speech therapists and occupational therapists, all of these departments do not have same requirements as respiratory therapists. Most just require a basis life support (BLS) certification if there is a requirement at all. Nurses are only required to maintain BLS and advanced life support competencies specific to their department patient demographic.

Therefore, respiratory therapists are not just an allied or an ancillary department but an equal partner in health care along with doctors and nurses, and that deserve equal recognition and compensation from the health care community. Once we are given this acknowledgment in the field of respiratory therapy, then and only then, will hospitals be able to achieve the much needed advancements in quality of patient care. Some examples of improvement would be to include respiratory therapists in departments such as discharge planning, education, and hospital administrative positions, to assist with the writing and implementation of future policies to further guide medical and academic institutions for optimal standards of care within the health care community. This is taking place in some hospitals, but at a snail's pace, I believe due to internal politics within the heath care community navigated by RN's and MD's. The only current avenue for respiratory therapists to further their career advancement is to obtain not only a Bachelor's degree, but a bachelor's in the field of nursing. Nursing over the years has in inadvertently stagnated advancement in health care on some levels by not allowing respiratory therapists in departments such as discharge planning, or any patient care plan departments, for that matter. Some examples of this would be patients in the home care setting or recently discharged patients being readmitted through the emergency department due to lack of required equipment or follow up care needed for a successful discharge.

As stated in the American Thoracic Society Journals "Approximately $15 \%$ of ICU patients are readmitted to a hospital within 30 days of hospital discharge. Patients requiring mechanical ventilation with a tracheotomy, patients discharged to a skilled nursing facility and patients with a high co morbidity burden were at the highest risk of readmission at 30 days". ${ }^{3}$ This unintended repetitive failure on the part of the heath care community is what fuels most, if not all respiratory therapists' disappointment in the field. This lack of lateral and upward movement within the field also contributes to what I believe is the main deterrent too many to not pursue higher levels of education within respiratory therapy. If the field of respiratory therapy is to survive and thrive in the future we will, collectively, have to demand a seat at the health care community table as an equal, not as ancillary partner. The profession of respiratory therapy has too much to offer the community to be ignored. My hope is that one day soon, respiratory therapy will be treated as an equal in the health care community, not looked down upon by our colleagues as subpar. Once this issue is addressed, it will most definitely have a positive impact on the health care system, from the administrative level steering health care policy to the betterment of the population's health care into the $21^{\text {st }}$ century.

\section{$2^{\text {nd }}$ Topic}

For this topic I will be discussing the rapid progression of the educational requirements needed to become a respiratory therapist along with the increased job expectations that fall within the scope of practice for a respiratory therapist. In the past, all that was required to become an inhalation technician was to be a hospital orderly or an equipment tech and be willing to undertake an on the job training program. This training was to help nursing and the physicians, to administer positive pressure broncho dilator therapy in the post op ward, and also to assist nurses and physicians throughout the hospital with the treatment of asthmatic and chronic pulmonary disease patients.

As science and technology gained ground over the years, so did the need for more qualified and advanced technicians in the pulmonary field. The certified respiratory therapist technician met that demand for a couple of decades, but due to advances in pulmonary medicine along with advances in highly technical life support equipment and with new methods of care, the need for even higher education is required. Today only the registered respiratory therapist program exists. This all started to change in the mid 1990's with the requirement of an associate's degree in science or applied science degree to obtain a license in respiratory care. "Today an associate degree in science or applied science is the minimal requirement to become a registered respiratory therapist. Training is offered at the postsecondary level by colleges and universities, medical schools, vocational-technical institutes and the armed forces. Most programs award an Associate or Bachelor's degree and prepare graduates for jobs as advanced respiratory therapists. A limited number of Associate degree programs lead to jobs as entry-level respiratory therapists. According to the Commission on Accreditation of Allied Health Education Programs (CAAHEP), 45 entry-level and 334 advanced respiratory therapy programs were accredited in the United States in 2006". ${ }^{4}$

More than twenty years later, in the year 2015, the NBRC finally eliminated the entry level certification exam and now only administers the single registry exam. Recently there has been a push again for the minimal requirement being a Bachelor's of Science in respiratory therapy to sit for the NBRC exam. The problem I see with that now, is not graduating enough students in the respiratory bachelor's program to become actual practicing therapists in the field of respiratory care. Most who graduate these bachelor programs then apply for the physician's assistant programs or medical school. Academia is now recognizing the medical communities' need for highly educated respiratory therapists for the future, and they are trying to find ways to remedy this in a timely and cost effective way. But this is proving to be very difficult.

For example, as an article written at the University of Loma Linda in California explains this dilemma. "Respiratory care professionals apply critical thinking skills in cardiopulmonary diagnostics and patient assessment to optimize decision making and delivery of patient care. In a time of high technology, increasing growth of the elderly population, and increasing numbers of patients with asthma and chronic lung disease, there is a greater demand for educated, skilled respiratory care practitioners. Advances in respiratory medicine, technology, and changes in health care have created a need for better educated respiratory care practitioners with diverse abilities. Job analysis research by the National Board for Respiratory Care reveals that employers now expect higher skill levels from respiratory education program graduates. Graduates need better critical thinking and problem solving skills and stronger verbal and written communication skills as well as computer literacy". ${ }^{5}$

Also in an article in the Respiratory Care Magazine, they discuss the job vacancies and the possibility of severe shortages in the 
Respiratory field in the coming future. "The RT vacancy rate for budgeted positions in 2005 was $8.6 \%$ (10,000 positions), which is an increase from $5.9 \%$ in 2000 . The 2005 AARC human resources study projected a need for 171,684 budgeted positions in 2010. In2015 the projected budgeted RT positions will exceed 200,000 if the growth in new positions continues at the 2005 rate. A severe manpower shortage will result if retirees are not replaced by graduates from respiratory therapy programs".

As stated before, some hospitals in the United States are recognizing the cost benefit of utilizing registered respiratory therapists for their own economic advantage to remain competitive in the health care industry. Some current examples of this would be hospitals utilizing respiratory therapists performing invasive line therapies such asperipherally inserted central catheter (PICC) linesand inserting and maintaining all central lines (simple and complex). These job listings are titled as Registered Respiratory Therapist Vascular Access Specialists. An example of this would be a resent job posting with the Banner Bay wood Hospital located in Mesa, Arizona: Registered Respiratory Therapist Vascular Access Specialist, job number 139909. Duties or job summary listed for this position is lengthy so bear with me on this one, it goes like this. This position independently provides and maintains peripheral and central venous access. This position conducts patient assessments and provides recommendations regarding care, serves as a resource person and specialist and provides assistance with departmental activities, quality improvement and a development of best practice guidelines.

\section{Essential functions}

Reviews labs, patient history and physician orders to determine appropriate line to be utilized for the procedure and/or identify potential issues that may arise or preclude the patient from being a viable candidate or require alternate form of vascular access. Collaborates with physicians to determine appropriate long-term access needs. Obtains patients authorization to perform the procedure. Inserts peripheral venous and/or arterial catheters to provide access or more complex vascular access as indicated.

i. Inserts and maintains peripherally inserted central catheter (PICC) lines according to department policy and procedures to include dressing changes, line reviews and declotting. Utilizes ultrasound technology to ensure accurate insertion of the PICC line. Reviews chest $\mathrm{X}$-rays to ensure accurate placement of the central venous catheter or device. Maintains sterile field throughout the insertion process to ensure quality outcomes. Maintains accurate, timely and appropriate documentation.

ii. Inserts and maintains all central lines (simple and complex) in the neck and chest according to department policy and procedures to include dressing changes, line reviews, port access and declotting. Utilizes ultrasound technology, advanced knowledge of anatomy and specialized insertion techniques to ensure accurate and appropriate insertion of the central line. Reviews chest x-rays to ensure accurate placement of the central venous catheter or device. Maintains sterile field throughout the insertion process to ensure quality outcomes. Maintains accurate, timely and appropriate documentation.

iii. Participates in ongoing monitoring of quality initiatives, department database, appropriateness and effectiveness of bundle compliance, acts as a change agent and participates in the development, interpretation, implementation and evaluation of quality goals/objective and quality management activities within the clinical service lines. May coordinate oversight of quality and safety standards, regulatory and accreditation requirements, as well as applicable professional standards.

iv. Acts as a resource to therapists and other healthcare practitioners regarding patient status, equipment and operational issues. Participates in interdisciplinary rounding, making recommendations for changes in therapy dictated by the patient's condition.

v. Provides training, orientation and patient education to staff, patients and families, in accordance with policy and practice guidelines. Assists in the development of departmental policies and procedures based on best practice.

vi. Assures the efficient operation of workflow of the department. Monitors and maintains an adequate inventory of supplies and material to ensure non-interruption of services. Provides maintenance of associated equipment as demonstrated through observation and documentation.

vii. May, on occasion, provide respiratory therapy services as prescribed and in accordance with established department/ hospital policies and procedures, including inserting and maintaining arterial lines, assisting in FDPAC and IAPB insertion and associated invasive cardiac outputs/profile and non-invasive cardiac outputs. Performs all functions according to established policies, procedures, regulatory and accreditation requirements, as well as applicable professional standards. Provides all customers of Banner Health with an excellent service experience by consistently demonstrating our core and leader behaviors each and every day.

\section{Minimum qualifications}

a. Associate or technical degree.

b. Successful completion of a training course in PICC and Banner Health Sims Lab training for CVC insertions.

Proof of good standing with the National Board for Respiratory Care (NBRC) as a Registered Respiratory Therapist (RRT). A current license in state practiced as required by state law. Basic Cardiac Life Support (BCLS) and Advanced Cardiac Life Support (ACLS) required. In-depth knowledge of clinical techniques, applications and equipment as typically obtained through 4 years of clinical experience as a RRT, including 1 year of independent PICC or CVC line insertions. Must possess highly effective human relation skills necessary to interface with patients, families, staff and other healthcare personnel". ${ }^{6}$

And there you have it, a typical example of how respiratory therapists are being utilized today in the hospital setting. Not the same model example of a respiratory therapist from a decade ago that represented as an ancillary or allied health professional. Now, the fact that we can be trained or even certified with additional onsite training in the local hospital setting toper form these invasive procedures in an intensive care unit enables the hospitals to recoup all of the costs and actually profit by billing the insurance companies for these invasive procedures at the same cost as if a physician performed the task. This leads me to believe that most accreditation agencies, hospitals and health insurance companies involved are aware of, and approve of this practice, because they note that all of these invasive patient care 
procedures are within the scope of practice of a registered respiratory therapist. Again as stated before, the minimal requirement to become eligible to sit for the registry board exam and to become a registered respiratory therapist today is an associate's degree in science. Further educational requirements and credentialing will depend on individual hospital policies and will also vary depending on state legislation and market forces.

For the past ten years or so, many universities have been offering the Bachelors of Science in respiratory therapy, taking advantage of the current economic times and the competitive nature of the job market that we are in now. But also by the request and the competitive nature of the health care industry to become joint commission accredited. ${ }^{7}$ Because of this many respiratory therapists are going back to school and signing up for programs that offer BS or a bridge program at the community college level with a university to receive a BS degree in respiratory therapy. But still, to this day many respiratory therapists still receive their BS in the nursing field to advance their careers in the medical field, and earn a reflective compensation rate for the time and monies spent to achieve such degree. To be completely honest, respiratory therapy as a profession is very limited in job progression and compensation. But in the field of nursing, further education is rewarded with lateral and vertical movement, along with compensation as described in an article by written by Beth Greenwood for demand media in the Houston Chronicle. The minimum educational requirement for an RT is an associate degree, although some RTs have a bachelor's degree. Typical courses include anatomy, physiology, chemistry, physics and microbiology, as well as supervised clinical experience. Although registered nurses may study the same subjects, the focus is different, as RNs must care for the whole patient. RNs have multiple options for their basic education, which include an associate degree, a nursing diploma or a bachelor's degree. RNs also have the opportunity to obtain additional education and become advanced practice nurses, with a broad scope of practice that includes medical functions. ${ }^{8}$

You will notice that RNs have the opportunity to obtain additional education to become advanced practice nurses so that they can broaden their scope of practice to perform more advanced or invasive procedures such as invasive line therapies, as CRNAs (Certified Registered Nurse Anesthetists).All this, without having to change their carrier fields entirely, as in the case of a respiratory therapist. This is a great example of how misunderstood the field of respiratory care is. On the one hand, we can be cross trained in the hospital setting to perform several invasive medical procedures based on hospital policy such as PICC or CVC line insertions, and OORAM (Out of Operating Room Airway Management) without the need for further education at the college level beyond the associate in science. It is recognized that these procedures are already within the scope of practice with an advanced boarded respiratory degree, also known as the RRT. For the field of respiratory therapy to grow and advance in the decades to come, recognition along with appropriate compensation is required for recruitment and retainment of well qualified individuals.

Recognition: The field of respiratory care should not be observed as just an ancillary or allied health partner, but as an equal, in the planning and administration of modalities for patient care, especially as advanced degrees are obtained in the field of health management. Some examples of positions that RRT's should be involved in and would be a great asset to would be to become more of an advisory/ pulmonary assistant in the clinical/home care environments, and with some post-secondary education at the masters degree level, similar to a physician assistant but with heavy emphasis in cardio pulmonaryintensive care. Also, RRT's should be deeply involved in patient care and discharge planning departments.

Compensation: The disparity in pay for comparable degreed professions in the clinical care setting is great, much worse than I had thought. If the disparity of wages is acceptably improved together with opportunities for advancement based on years of experience, acknowledged science and management degrees, along with merit and leadership qualities of the individual in the medical field are addressed, then you will have the tools for recruitment for future talent in the field. Also if these actions are addressed, the positive benefits in the patient population will improve greatly, not to mention the hospitals and insurance company's bottom line.

\section{$3^{\text {rd }}$ Topic}

For this argument, I will be comparing registered nurses to registered respiratory therapists at the associate degree level, to exhibit the disparity in pay between the two health care fields. Even though respiratory therapists work alongside medical doctors and registered nurses with bachelors and master's degrees in all critical care areas in the hospital. Also, I will display the disparity in pay between respiratory therapists throughout the nation between private and public sectors. The reason I selected the nursing department and not any of the other ancillary or allied health departments is because the only other health care professional other than a nurse that has as much patient bedside contact on a daily basis is the respiratory therapist. I will be providing data on the pay disparity over time between nurses and respiratory therapists. This information will demonstrate the reason why there is a lot of frustration in the respiratory therapy community. If appropriate compensation, along with proper utilization of the respiratory therapist were to happen, thus more qualified candidates would apply for respiratory therapy programs, resulting in an improved pool of well qualified therapists available for the health care community nationwide. The disparity in pay between these two career fields amid the years of 1988-2012 nationwide has varied significantly, between $7 \%$ to $17 \%$, as seen on Figure 1 below this data was acquired from the Occupational Outlook Handbooks, indeed.com, Payscale.com, Salary.com and BLS.gov. ${ }^{9-23}$

\section{National history of respiratory vs nursing pay disparity}

1988

Median pay

ASRRT: \$19,632

ADN: $\$ 23,100$

$=15 \%$ disparity in pay.

1992

Median pay

ASRRT: \$32,084

ADN: $\$ 34,424$

$=6.8 \%$ disparity in pay.

1998

Median pay

ASRRT: $\$ 34,830$ 
ADN: $\$ 40,690$

$=14.4 \%$ disparity in pay.

2005

Median pay

ASRRT: $\$ 45,140$

ADN: $\$ 54,670$

$=17.4 \%$ disparity in pay.

2012

Median pay

ASRRT: $\$ 55,870$

ADN: $\$ 65,470$

$=14.7 \%$ disparity in pay.

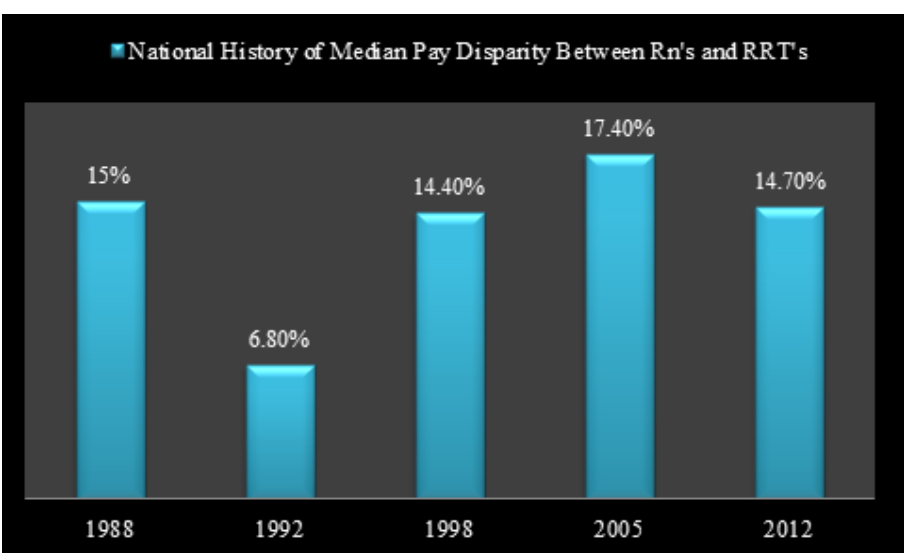

Figure I National History of Median Pay \% Disparity between Rn's and RRT's.

Now I will exhibit pay inconsistencies averaged between respiratory therapists and registered nurses that work in the public verses private sectors on a national and local level. With emphasis on the Phoenix V.A, since that is where I'm employed. Due to the recent unwanted media attention involving the Phoenix VA, corrective actions were implemented which resulted in added government funding to employ more doctors and nurses. In their haste the government left other vital health care workers in the V.A. hospitals out of the loop, for example, Physician assistants, Radiation Technologists, Licensed Practical Nurses and Respiratory Therapists, just to name a few. The pay raises that were awarded to nurses were effective November of 2014 and varied between $7 \%$ and $15 \%$, depending on what Title-38 G scale the nurse was on, G1-15\%, G2-10\%, and G3-7\%. Registered Respiratory Therapists at the Phoenix VA received $0 \%$ pay raise during that same period in time. I presented this disparity to administration in January of 2015 and we were assured that this would be addressed as soon as possible. This was my motivation to write this paper.

At present in the example below in Figure 2 you will note the steady decrease in disparity in pay between nurses and respiratory therapists with similar educational backgrounds. This is also seen as experience increases over time on a national level. This is based on the need for recruitment and retainment of experienced nurses and respiratory therapists. The following information below represents an averaged federal and private sector pay scale comparison for RRT's and RN's. You can see that the issue of pay disparity is being addressed nationally, evident of the median pay disparity reduction from 2014 of $14.1 \%$ to a decrease in disparity in 2015 of $10.8 \%$. See Figure 2 below. But locally here in Arizona, this is not the case. Disparity in the Phoenix area is still great, and I will demonstrate this in the following examples. At least on a national level, the disparity in pay between nurses and respiratory therapists are headed in the correct order of greatest to least disparity in the way of experience over time. Meaning, the disparity decreases between the fields of respiratory and nursing due to the need to retain respiratory therapists with more experience (Occupational Outlook Handbooks, Payscale.com, Salary. com, indeed.com and BLS.gov. ${ }^{9-23}$

\section{National Hospitals}

\section{Entry level}

RRT: \$31,867

RN: $\$ 38,880$

$=18 \%$ disparity in pay.

\section{Median pay}

RRT: $\$ 47,911$

RN: \$55,745

$=14.1 \%$ disparity in pay.

Top pay scale

RRT: $\$ 68,456$

RN: \$78,501

$=12.8 \%$ disparity in pay.

2015 National Hospitals

\section{Median pay}

RRT: \$61,795

RN: \$69,307

$=10.8 \%$ disparity in pay.

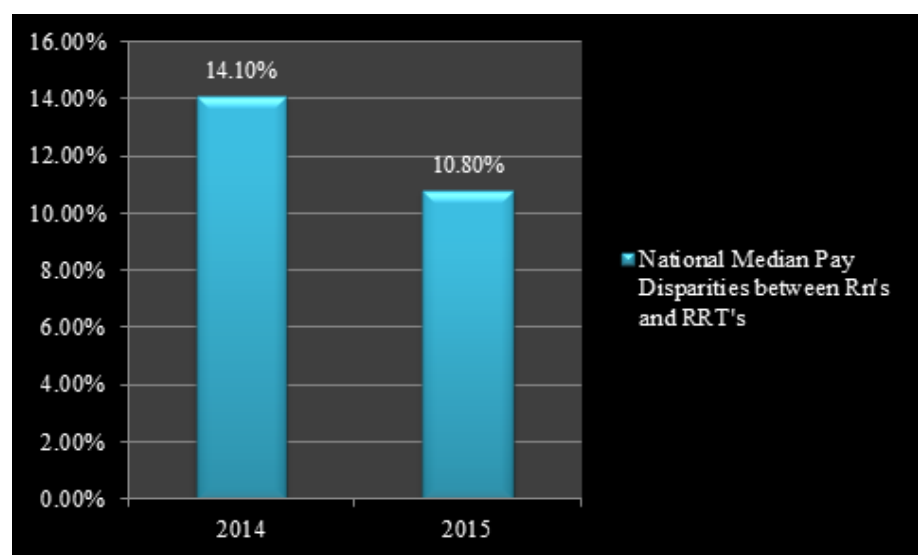

Figure 2 National Median Pay \% Disparities between Rn's and RRT's.

Now, you will note in the next example that the disparity in pay between nurses and respiratory therapists in the recruitment of new graduates in the Phoenix area in 2014 was $27 \%$. The disparity in pay at the top end of the scale for retainment purposes between RN's and RRT's in that same year was $31.3 \%$. See in Figure 3 below. However, 
during that same year the national average in disparity involving recruitment and retainment between nurses and respiratory was $18 \%$ at the entry level and $12.8 \%$ for retainment. This is a little closer to an acceptable disparity average for recruitment and retainment of qualified personnel. Again, the disparity in median pay at the national level from 2014 to 2015 between nurses and respiratory therapists has decreased from $14.1 \%$ to $10.8 \%$. But in the state of Arizona the median pay disparity has been pretty consistent at $10.8 \%$, between entry level and experienced care practitioners during the years of 2014 to 2015. This I believe was done intentionally to maintain labor costs within the hospital setting in the state of Arizona. By targeting a median pay of $10.8 \%$, this sustains an illusion of pay comparable to the national average and at the same time maintaining a satisfactory level of recruitment and expertise in the hospitals in the Phoenix area (Occupational Outlook Handbooks, Payscale.com, Salary.com, indeed.com and BLS.gov. ${ }^{9-23}$

\section{Phoenix area Hospitals}

\section{Entry level}

RRT: $\$ 39,589$

$\mathrm{RN}: \$ 54,259$

$=27 \%$ disparity in pay.

\section{Top pay scale}

RRT: \$64,768

RN: $\$ 94,303$

$=31.3 \%$ disparity in pay.

\section{Median pay for phoenix area hospitals}

\section{Median pay}

RRT: $\$ 60,136$

RN: $\$ 67,449$

$=10.8 \%$ disparity in pay.

\section{Median pay}

\section{RRT: $\$ 60,435$}

RN: $\$ 67,782$

$=10.8 \%$ disparity in pay.

The following data gathered below will show that the disparity in pay between RN's and RRT's in the south west region, including Arizona, are parallel to the national average in the year 2015 of 10.8\%. (Occupational Outlook Handbooks, Payscale.com, Salary. com, indeed.com and BLS.gov. ${ }^{9-23}$

\section{Neighboring states 2015}

\section{California Hospitals}

\section{Median pay}

RRT: $\$ 75,988$

$$
\mathrm{RN}: \$ 67,752
$$

$=10.8 \%$ disparity in pay.

\section{Nevada Hospitals}

Median pay

RRT: \$61,609

RN: $\$ 69,099$

$=10.8 \%$ disparity in pay.

\section{New Mexico Hospitals}

Median pay

RRT: \$56,925

$\mathrm{RN}: \$ 63,845$

$=10.8 \%$ disparity in pay.

\section{Utah Hospitals}

Median pay

RRT: $\$ 58,748$

RN: $\$ 65,890$

$=10.8 \%$ disparity in pay.

\section{Arizona Hospitals}

Median pay

RRT: $\$ 60,435$

RN: \$67,782

$=10.8 \%$ disparity in pay.

Now we will look at the disparities in pay between respiratory therapists only, private sector verses the public sector (VA).On a national level, the disparity in pay between the government (VA) and the private sector as far as retainment compensation or the top of the pay scale there remains a $16 \%$ disparity in pay. In the state of Arizona as a comparison the disparity in pay at the top of the pay scale between government (VA) and the private sector still remains at the $18 \%$ level. Many other states are probably in a similar situation but I did not look in depth in each state. The VA has, in my opinion, other than flat out ignoring the situation deliberately, or being completely ignorant in general, has intentionally not kept pace with the private sectors pay scale for respiratory therapists, ever. Recently the VA has acknowledged this great disparity and they are somewhat resolving the issue by utilizing a specialty pay scale to correct the current pay. This is only being addressed now due to the recent agitation from the staff therapists at the VA hospital in Phoenix Az. Guaranteed, if we remained silent, this would have never been addressed. Even with resent increases in compensation locally in the Phoenix area, the disparity in pay between the state of Arizona and the national level for many respiratory therapists, I believe, is still at a great imbalance.

I'll give you a personal example of mine of when I first entertained the idea of employment within the Department of Veteran Affairs. Hopefully you can better understand my thoughts. Way back in1996, with less than one year in the field of respiratory care, I entered the Loma Linda VA Hospital in southern California with the intention that I would be applying for a respiratory care position recently posted locally in the news paper. This was the first place I truly considered for a long, successful career in health care. At the same time, giving 
a little back to the veterans (being one myself,) was important to me. The staff in the respiratory department furnished me with the GS (Grade Step) pay scale upon request. They indicated where I would be on the scale if I was to accept a position as a new hire RRT. I would have been at the entry level of a GS 8-1 \$28,071 annually with a $9.39 \%$ locality increase at that time. I was shocked, to say the least. I was earning at that same time $\$ 33,280$ annually, changing lighting ballasts in high schools and other government buildings for a private contractor for the US government. How ironic. On top of that, three years prior, I worked on aircraft earning $\$ 35,360$ plus overtime at a Long Beach California plant, and close to $\$ 50,000$ not including lodging and meals tax free while subcontracting with a U.S. based company for the Spanish Air Force. But to work in a VA hospital in California, in an intensive care unit, with life and death issues on human beings, I was only going to earn $\$ 28,071$ a year? My jaw hit the ground!!!! Where are our priorities? And how do they expect to attract the brightest in the field? Feeling a numbness of reality coming over me, like getting hit in the face with an ice-cold bucket of water, I left the VA hospital that day over come with surprise and empathy for the entire respiratory staff there. I also had a sense of embarrassment that the United States Government would have such a low priority and concern for the men and women who served this country honorably.

Back then, the VA's implementation of both the recruitment and retainment pay scales were, let's just say, well below community standards. Flash forward nineteen years later, I'm still in shock. To give the government credit, they have recently addressed the recruitment pay levels somewhat, and are now being forced to address the entire pay scale itself. Where the VA still lacks to this day is in the retainment pay scale levels on a national average. The VA hospitals have always used the excuse of a great benefits platform to defend the pay scale in the past. But after years of benefit cuts along with stagnant pay increases, which amount to pay cuts if cost of living is incorporated in this equation.

At the same time watching other health care professionals such as nurses, who we work alongside with, routinely get and maintain comparable wages with the private sector, not only in recruitment but also in the extent of retainment, has had a negative impact on morale within the respiratory care department within the VA system. We as respiratory therapists and care practitioners have an obligation to voice our grievances now. Below are more exiting examples of national and state (Arizona) averages at the entry level and top level for respiratory therapy pay. Again these averages are between government and private hospitals. You will notice that the recruitment levels on a national average are very liberal today, but the retainment practices are still lacking. When you look at the disparity in Phoenix AZ, where I am located, you can understand my dissatisfaction. Again, on a national level the corrected government pay scale currently on the entry level supersedes the private sector average by $16 \%$. But at the top of the scale the government pay scale still remains below the national average, versus the private sector by $16 \%$, the exact opposite. To cover the cost of the exorbitant retirement benefits of the government employees, I'm sure. I could be completely wrong but I doubt it. To top things off rumor has it, that possibly more benefits will be cut in the form of actual pay cuts due to increased employee contributions to the pension fund (FERS), to cover the costs of the current pensioners, future retirees and the cost of new hires as part of a recent hiring push to address the current situation with the VA system.

In the Phoenix area where all this unwanted negative attention began, the disparity in pay for respiratory therapists between the private and public sector is still bad across the board, from both a recruitment and retainment perspective. There is a $12.7 \%$ disparity at the entry level and $18 \%$ disparity at the top of the pay scale as seen in Figure 4 below. (Occupational Outlook Handbooks, Payscale.com, Salary.com, indeed.com and BLS.gov, opm.gov, va.gov. ${ }^{9-23}$

\section{National average va hospitals vs private hospitals}

\section{Entry level}

VA RRT: \$38,007

Private RRT: $\$ 32,326$

$=16 \%$ disparity in pay for the private sector.

\section{Top pay scale}

VA RRT: \$57,691

Private RRT: $\$ 68,456$

$=16 \%$ disparity in pay for VA.

\section{Phoenix average: VA hospital vs Private hospitals}

\section{Entry level}

VA RRT: $\$ 44,377$

Private RRT: $\$ 50,857$

$=12.7 \%$ disparity in pay for VA.

\section{Top pay scale}

VA RRT: $\$ 57,691$

Private RRT: \$70,234

$=18 \%$ disparity in pay for VA.

To finish with the disparity discussions, we are going to look at the disparity in pay between registered nurses and registered respiratory therapists with the same educational background and critical care patient exposure within the Phoenix VA Medical Center. This comparison exhibits the gross disparity to the point of embarrassment. My coworkers in the nursing field couldn't even believe it. They had no idea how low our pay scale is compared to their pay scale and they also had no clue how poor our educational opportunities and chances for career advancement are compared to the nursing department. Why is it acceptable to reimburse nurses at the VA Medical Center in Phoenix AZ with equal or higher pay than their counterparts in the private sector, but choose to exclude respiratory therapists in the same VA hospital? Don't get me wrong, I applaud the pay scale for the nursing department; the VA hospitals nationwide should pay the best to get the best. My question is, why respiratory therapists are still not acknowledged with the same approach? Below is the breakdown focusing on the disparity in pay between registered respiratory therapists and registered nurses at the Phoenix VA Medical Center, which is jaw dropping to say the least. I always knew that there was a large inequality here at the Phoenix VA between nurses and respiratory therapists, but when I started looking at the pay scales and doing the comparisons myself, let's just say I had a moment of pause. There is a $28 \%$ disparity at the entry level and a $39 \%$ disparity at the top of the GS pay scale. Figure 3 shows the 2014 VA pay scale comparison and Figure 4 shows the 2015 pay scale comparisons post specialty pay adjustment for the respiratory care department at the Phoenix VA. ${ }^{24,25}$ 


\section{Phoenix VA hospital RN vs RRT}

\section{Entry level}

RRT: GS 8/1 \$44,377

RN: G1 Step $1 \$ 61,748$ (post 15\% raise effective 11/14/14).

$=28.2 \%$ disparity in pay.

Top pay scale

RRT: GS 8/10 \$57,691

RN: G1 Step $19 \$ 95,084$ (post 15\% raise effective 11/14/14).

$=39.4 \%$ disparity in pay (Figure 5).

\section{Phoenix VA Hospital RN vs RRT}

\section{Entry level}

RRT: GS 8/1 \$49,903(post 30\% raise effective 4/15/15).

RN: G1 Step $1 \$ 61,748$ (post $15 \%$ raise effective 11/14/14).

$=19.2 \%$ disparity in pay.

\section{Top pay scale}

RRT: GS 8/10 \$64,879 (post 30\% raise effective 4/15/15).

RN: G1 Step $19 \$ 95,084$ (post 15\% raise effective 11/14/14).

$=31.8 \%$ disparity in pay [Figure 6].

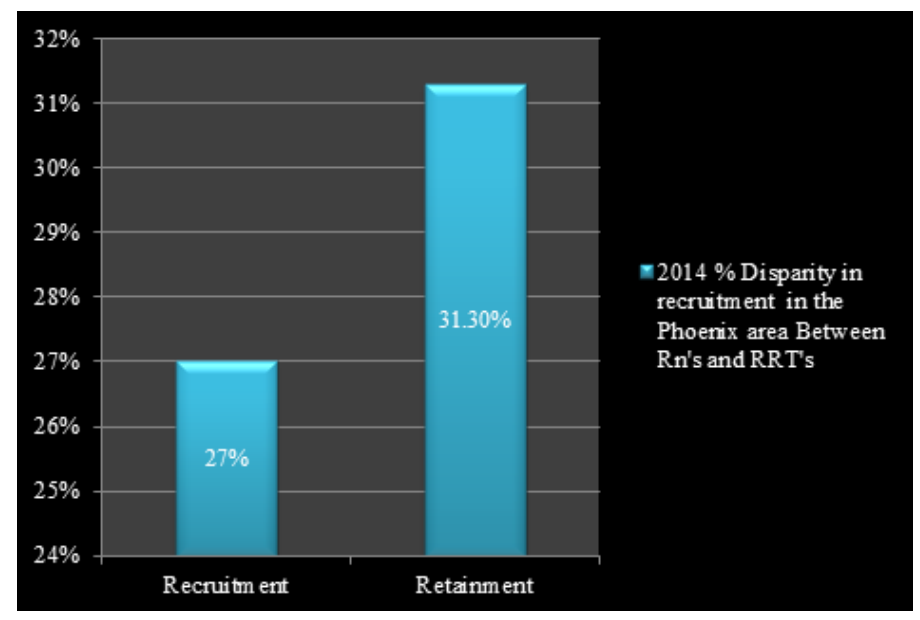

Figure 32014 \% Disparity in Recruitment and Retainment in the Phoenix area.

These increases for the nurses will put their pay equal to or above local averages for nurses in the phoenix area. This will enable the VA hospital in Phoenix to compete with other hospitals in the area and facilitate the recruitment and retainment of qualified professionals. Sadly, the administration again overlooked the respiratory therapists, assuming all would be fine. Maybe they thought we wouldn't notice or have the resolve to address this issue. Most likely, the administration never even gave it a thought because we were never even considered as an equal critical element in today's health care environment. I can't let this issue pass this time. I will calmly and methodically build a coalition of professionals in academia and in the medical field by using current information and facts with supporting documentation to remedy this issue. It's not just the pay disparities between respiratory therapists in the private sector verses the public sector or the disparities in general between nurses and respiratory therapists with similar educational backgrounds. It is the mismanagement of the resources available for optimal patient outcomes that really bothers me the most. The disparity in pay of respiratory therapists between the Phoenix VA hospital and the private sector hospitals within the local community will be addressed, and hopefully remedied in the near future to at least match local pay scales or come close. But the disparity in pay between nurses and respiratory therapists with equivalent educational backgrounds along with proper utilization of respiratory therapists in the health care community nationwide, will take some time to resolve.

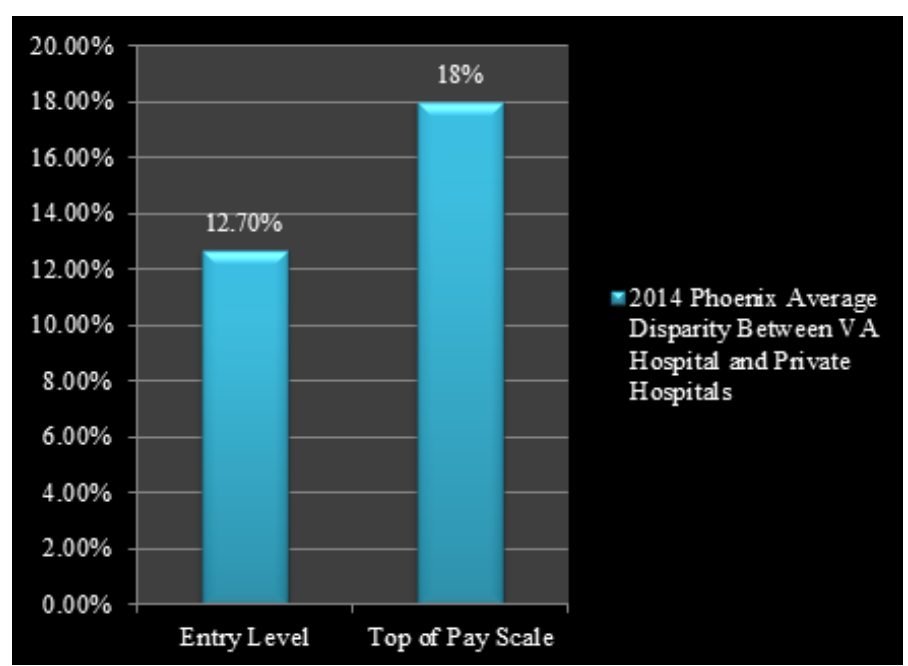

Figure 42014 Phoenix average disparity between VA Hospital and Private Hospitals.

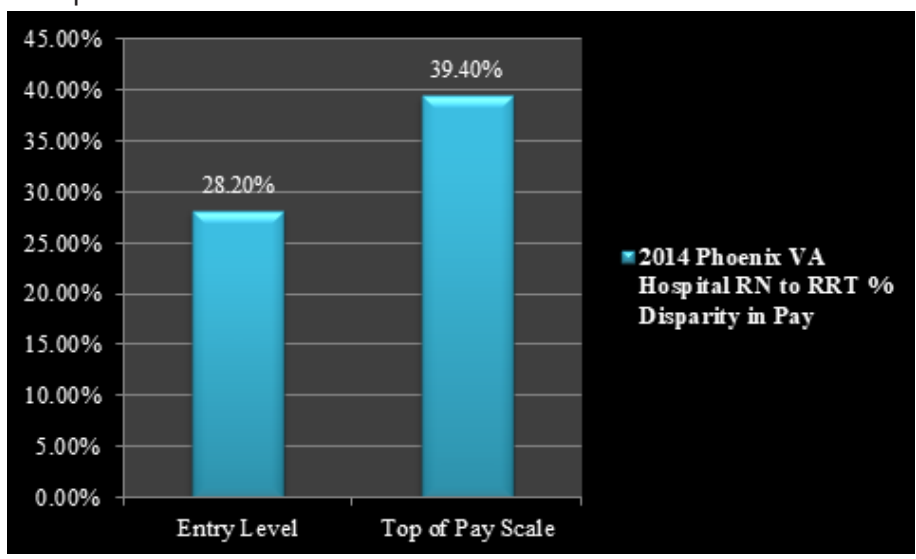

Figure 52014 Phoenix VA hospital RN to RRT \% Disparity in pay.

Below is information provided by the human resources department and the nursing department at the Phoenix VA Medical Center reflecting the recent much needed pay increases for health care professionals at the hospital. Also presented below is the average disparity in pay between respiratory therapists here in Phoenix and at the national level within the VA Medical system. Keep in mind that Phoenix Arizona is the $6^{\text {th }}$ largest city in the United States with over 1.5 million people and with over 78,000 of them veterans. Yet there is a 3.6\% disparity in pay in comparison with the national VA average. With recent attention along with focused protest within the respiratory department lately, we were able to make a valid argument on the disparity in pay here at the Phoenix VA. As a conclusion were able 
to encourage our supervision and upper management though human resources to address and correct this disparity in pay. As of March 2015 we were able to close the discrepancy with other respiratory therapists in the Phoenix area to almost match pay scales within the private sector. Now we will be more competitive and hopefully be able to recruit well qualified therapists in the future and be able to increase our quality of care here at the Phoenix VA. ${ }^{24,26,27}$

\section{Phoenix VA hospital pay increases}

RN pay increase effective Nov 2014

G1 15\%

G2 10\%

G3 7\%

RRT pay increase effective Nov 2014

GS $7 / 8 / 9 / 100 \%$

RRT pay increase effective March 2015

GS $7 / 8 / 9 / 1030 \%$

\section{National VA Hospital RRT GS -8 Averages}

\section{Salary table 2014}

GS-8/10 national average is $\$ 59,834$

Phoenix AZ GS-8/10 is $\$ 57,691$

For a disparity of $3.6 \%$

\section{Salary table 2015}

Phoenix AZ: GS 8/10 $\$ 64,879$ post $30 \%$ increase on the general scale

For a $4.2 \%$ above the current national federal average.

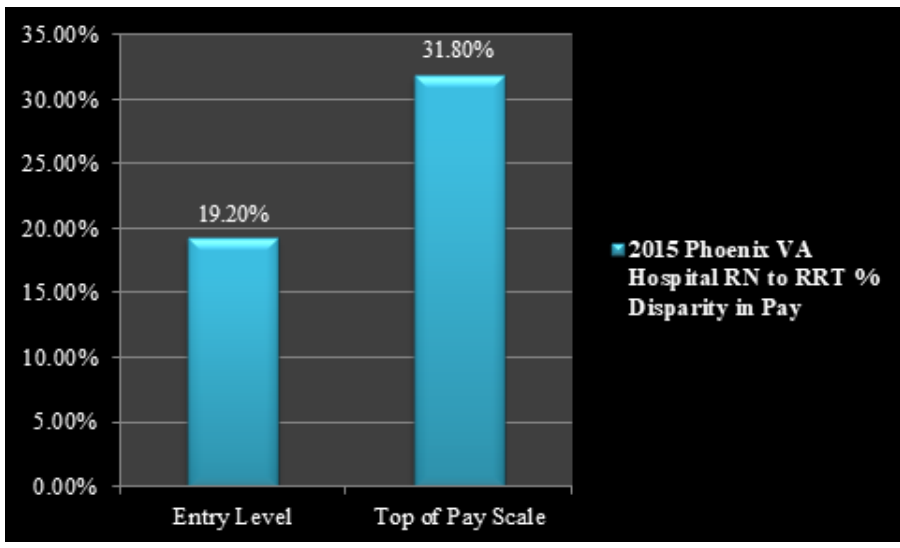

Figure 62015 Phoenix VA Hospital RN to RRT \% Disparity in Pay.

\section{Conclusion}

In the end, all this talk of wages, salaries and the clear disparities in pay between registered respiratory therapists and registered nurses with similar educational backgrounds in the health care field is just a surface argument of a grander issue. Yes, wages are important as a form of compensation for work performed or talents needed based on a scale of supply and demand, thus being able to recruit talented individuals into the career field. But in this paper I would like the focus to be more on the significance and the impact that a respiratory therapist has on all health care capacities including critical care, long term care, home care, diagnostic and preventative care, just to name a few. I used registered nurses as a comparison to respiratory therapists on pay differences and educational similarities only because nurses and respiratory therapists work alongside with each other in the hospital setting the most compared to any other health care professional. And registered nurses and respiratory therapists have similar minimal didactic and clinical requirements to achieve state and national credentialing to work in the medical field. As far as the role of the respiratory therapist, it has evolved into much, much more than just an ancillary or an allied health care partner over the last four decades. We have, as a profession, progressed very rapidly along with the technological advances in life support equipment, into a more sophisticated care practitioner, resulting in a positive outcome for the patient and the community in general. Let me be clear, my main argument in this paper is that the field of respiratory care has evolved from ancillary or allied health to an irreplaceable form of practitioner and a crucial partner in health care. Compensation along with inclusion in the health care community to update patient care policy has not kept pace with this occurrence. The only reasons I can explain this is just a general lack of education or exposure within the health care community of what exactly a respiratory therapist is and does.

For this I fault our selves, for not being more assertive in the public relations department. We need, as a collective in the respiratory care field, to find a way to get the message out by using all forms of media as possible. This will be the only way to shed light on the issue, and bring about positive change desperately needed in the health care community. The only responses to my argument I receive from health care administrators is limited to say the least. In general, it basically comes down to supply and demand and or budget constraints. Information or lack of information, that administrators must determine wages for recruitment and retainment is based on much outdated information, or misinformation, on exactly what a respiratory therapist can accomplish daily in the health care setting. The only other possibility is that the administrators identifies exactly what a respiratory therapists is and they, being administrators and or private investors, knowingly taking full advantage of this money saving, profiteering technique. I hope I'm wrong on the later but most likely, I'm not.

The tier of patient responsibility or patient contact goes as such, non-ancillary or direct patient care, first tier. And second tier, or ancillary, involved with limited direct patient care in the critical care setting. First tier consist of MD, PA, NP, CRNA, RN, RRT, LPN or LVN/CNA. Second tier providers I believe consist of professionals in the fields of X-Ray, Lab technicians, Speech therapy, Nutrition, Occupational Therapists, and Pharmacy. Although all of these occupations are important to patient outcomes, they don't have the same level of stress and exposure as the first tier care practitioners. This demonstrates that RRT's are not truly an ancillary or allied health practitioner any longer, as is still perceived in the health care community to this day. Registered respiratory therapists are currently an equal and important partner in the health care community by providing critical input with patients in the health care environment.

Also as stated before on the list of first tier practitioners, RRT's are the only care practitioners that consistently on a daily basis take care 
of the most critical patients in all hospitals in the United States, public and private, day in and day out. RN's and MD's do not. For example, respiratory therapists respond to all code blues in a hospital 24/7, other health care providers in tier one do not. Md's and RN's only respond to code blues if it is their direct patient or coverage area that specific shift, which result in an obvious less exposure. Respiratory therapists have to respond to all code blues and rapid responses, thus resulting in an obviously increased exposure rate to critical life and death situations. Also, most care practitioners only have special or advanced training specific to the age demographic of patient they work with on a consistent basis.

Respiratory therapists are required to maintain multiple if not all advanced training certifications on a bi-annual basis for multiple or all age specific demographics. This is because respiratory therapists are required, and are expected to work, in all critical care units and with all age demographics, occasionally within the same shift. Examples of these certificate programs would be BLS (Basic Life Support or CPR), ACLS (Advanced Cardiac Life Support), PALS (Pediatric Advanced Life Support), NRP (Neonatal Resuscitation Program), and advanced airway management programs such as OOORAM (Out Of Operating Room Airway Management).These requirements are specifically tailored to the institution at hand. Doctors and nurses on the other hand only maintain age specific advanced care certifications detailed to their work environments.

In other words, a pediatric nurse in a pediatric ICU will most likely only have to maintain a PALS card along with a BLS card bi-annually, not a NRP or ACLS certificate. Same goes for physicians. In most cases doctors and nurses in hospitals are not required to complete all advanced critical care certificate programs on abi-annual basis for maintaining their positions of employment. But respiratory therapists in most cases in virtually all hospitals are required to complete all advanced critical care certificates on a bi-annually basis to maintain employment within the health care facility.

In the end, my vision, or hope is that in the near future respiratory therapists are recognized and utilized to their full potential in the health care community. And that one day there will be a registered respiratory therapist located not only in cardio pulmonary or respiratory care departments in the hospital but also in other departments that are greatly lacking in the pulmonary area such as hospital education departments, patient care and planning, discharge planning, and tele health just to name a few. Also a registered respiratory therapist should be more involved in hospital policy initiation, implementation and review within the administrative level. These enhancements would not only greatly improve patient outcomes, but it will also improve cost effectiveness at the health care facility and insurance provider levels. I do agree that additional research is needed to actually prove my thoughts on this subject, but with my years of clinical experience I predict that this would be supported without reservation. I just believe that as a society we need to constantly review and improve our thought processes and be open-minded enough to make the necessary changes with minimal risks. This is the only way to advance as a civilization. Greed and ignorance slows this natural process to a frustrating pace. But if we all are able to realize this, eventually we will succeed. ${ }^{28-31}$

\section{Acknowledgements}

This research was supported and partially supported by all my references listed on pages 43 and 44 of the paper. They all provided insight and expertise that greatly supported my research, although they may not agree with all the interpretations/conclusions of my paper. I also would like to thank my wife for putting up with me over the many months while I wrote this paper.

\section{Conflicts of interest}

There are no conflicts of interest.

\section{References}

1. AARC. The History of Respiratory Therapy. American Association for Respiratory Care, USA.

2. https://www.nbrc.org/crt/pages/default.aspx

3. ht tp://www.atsjournals.org/doi/pdf/10.1164/ ajrccmconference.2014.189.1_MeetingAbstracts.A2527

4. Respiratory Therapy.

5. Respiratory Care.

6. Registered Respiratory Therapist Vascular Access Specialist - 139909.

7. http://www.ucdmc.ucdavis.edu/nurse/magnet/faq.html

8. Respiratory Therapist Vs. Registered Nurse.

9. http://www.payscale.com/research/US/Job=Respiratory_Therapist/ Hourly_Rate 11/2014.

10. http://www.payscale.com/research/US/Job=Registered_Nurse_(RN)/ Hourly_Rate 11/2014.

11. http://www.bls.gov/oes/2011/may/oes291111.htm 11/2014

12. http://www.bls.gov/oes/current/oes291126.htm 11/2014

13. http://www1.salary.com/Registered-Respiratory-Therapist-salary.html $11 / 2014$

14. http://www1.salary.com/Registered-Nurse-Salary.html 11/2014

15. Registered Respiratory Therapist Salaries.

16. http://www.opm.gov/policy-data-oversight/pay-leave/salaries-wages/ salary-tables/pdf/2014/PX.pdf 11/2014.

17. http://vaww.va.gov/ohrm/pay/NURS_LPS/636-799.pdf 11/2014.

18. DIANE Publishing Company (1994-1995) Occupational Outlook Handbook. USA, p. 175-179.

19. Bureau of Labor Statistics (1990-1991) Occupational Outlook Handbook. USA, p. 160-165.

20. Bureau of Labor Statistics (2000-2001) Occupational Outlook Handbook. USA, p. 210-214.

21. http://www.bls.gov/ooh/healthcare/home.htm2012

22. http://www.opm.gov/policy-data-oversight/pay-leave/salaries-wages/ salary tables/pdf/2014/saltbl.pdf

23. http://www.indeed.com/salary

24. http://www.opm.gov/policy-data-oversight/pay-leave/salarieswages/2015/general-schedule/

25. http://vaww.va.gov/ohrm/pay/NURS_LPS/636-799.pdf

26. http://www.va.gov/OHRM/Pay/

27. http://intranet.visn18.med.va.gov/phoenix/ 
28. http://digitalscholarship.unlv.edu/cgi/viewcontent. cgi article $=2778 \&$ context $=$ thesesdissertations

29. Shaw KL (2012) Credentialing Success in Respiratory Therapy Education: Revisiting Bourdieu's Concepts of Field and Capital. pp. 1-153.
30. http://www.eda-bc.com/documents/COLI2015_Q2.pdf

31. http://www.state.gov/m/fsi/tc/79700.html 